\title{
Trait biogeography of marine copepods - an analysis across scales
}

\author{
Brun, Philipp Georg; Payne, Mark R; Kiørboe, Thomas
}

\section{Published in:}

Ecology Letters

Link to article, DOI:

10.1111/ele.12688

Publication date:

2016

Document Version

Peer reviewed version

Link back to DTU Orbit

Citation (APA):

Brun, P. G., Payne, M. R., \& Kiørboe, T. (2016). Trait biogeography of marine copepods - an analysis across scales. Ecology Letters, 19(12), 1403-1413. https://doi.org/10.1111/ele.12688

\section{General rights}

Copyright and moral rights for the publications made accessible in the public portal are retained by the authors and/or other copyright owners and it is a condition of accessing publications that users recognise and abide by the legal requirements associated with these rights.

- Users may download and print one copy of any publication from the public portal for the purpose of private study or research.

- You may not further distribute the material or use it for any profit-making activity or commercial gain

- You may freely distribute the URL identifying the publication in the public portal

If you believe that this document breaches copyright please contact us providing details, and we will remove access to the work immediately and investigate your claim. 


\section{Trait biogeography of marine copepods - an analysis across scales}

2 Running title (45 char): Trait biogeography of marine copepods

3 Philipp Brun ${ }^{1, *}$ Mark R. Payne ${ }^{1, \mathrm{a}}$, and Thomas Kiørboe ${ }^{1, \mathrm{~b}}$

$4 \quad{ }^{1}$ Centre for Ocean Life, National Institute of Aquatic Resources, Technical University of

5 Denmark, Kavalergarden 6, DK-2920 Charlottenlund, Denmark

$6 *$ Corresponding author:

$7 \quad$ Email: pgbr@aqua.dtu.dk

8 Phone: +4535883480

$9 \quad$ Fax +4535883333

10 a mpay@aqua.dtu.dk

11 b tk@aqua.dtu.dk

12 Keywords (10): Trait biogeography, copepods, marine zooplankton, global, body size,

13 myelination, offspring size, feeding mode, integrated nested Laplace approximations,

14 Shannon size diversity

15 Type of article: Letter

16 Statement of authorship: All authors were involved in the design of the technical set-up of the

17 study. PB compiled and analyzed the data and prepared the manuscript with contributions and

18 support from the other authors.

19 Number of words in the abstract: (147/150):

20 Number of words in the main text (excl. acknowledgements, references, legends):

$21(4992 / 5000)$

22 Number of words in text boxes: (561/750)

23 Number of references: $(55 / 50)$

24 Number of textboxes/figures/tables (max 6 in total): 6 
Functional traits, rather than taxonomic identity, determine the fitness of individuals

27 in their environment: traits of marine organisms are therefore expected to vary across the

28 global ocean as a function of the environment. Here, we quantify such spatial and seasonal

29 variations based on extensive empirical data and present the first global biogeography of key

30 traits (body size, feeding mode, relative offspring size and myelination) for pelagic copepods,

31 the major group of marine zooplankton. We identify strong patterns with latitude, season, and

32 between ocean basins that are partially (approximately 50\%) explained by key environmental

33 drivers. Body size, for example, decreases with temperature, confirming the temperature-size

34 rule, but surprisingly also with productivity, possibly driven by food-chain length and size-

35 selective predation. Patterns unrelated to environmental predictors may originate from

36 phylogenetic clustering. Our maps can be used as a test-bed for trait-based mechanistic

37 models and to inspire next generation biogeochemical models. 


\section{Introduction}

Studying the distribution and abundance of organisms is the key task in ecology (Begon et al. 2006). In recent decades, the growing availability of observational data and empirical models has increasingly allowed the pursuit of this task on large spatial scales. In particular the distribution patterns of individual species and their links to the physical environment have been studied intensively (Elith \& Leathwick 2009). However, a major challenge for such macro-scale studies is the mechanistic linking of the observed patterns to the processes that drive them (Keith et al. 2012). One powerful way to identify such links is the trait-based approach, because the functional traits of an organism, rather than its taxonomic identity, determine its fitness in a given environment. The trait-based approach assumes that organism fitness is based on success in the fundamental life missions feeding, survival and reproduction, and that the outcome of each of those missions depends on a few key traits. These key traits are interrelated through trade-offs and their optimal expression is determined by the environmental conditions (Litchman et al. 2013).

The trait-based approach in biogeography is well established for primary producers but its potential for animals has rarely been exploited. The trait-based approach has a long tradition in plant ecology (e.g., Westoby et al. 2002) and has also been used to describe the distributions of phytoplankton (e.g., Edwards et al. 2013). Besides providing ecological insight, trait biogeographies have fostered a more realistic incorporation of primary producers into global vegetation and ocean circulation models and thus have advanced biogeochemistry and climate science research (Scheiter et al. 2013; Brix et al. 2015). However, trait biogeographies for animals are uncommon, although they may be equally valuable. This is particularly evident for marine zooplankton, and their dominant members, the copepods 
62 (Barton et al. 2013b). Marine copepods are ubiquitous, typically dominate the biomass of zooplankton communities, and play a key role in pelagic food webs (Verity \& Smetacek 1996). For this group traits and associated trade-offs are relatively well understood (Kiørboe 2011) and comparably rich observational data exists (O’Brien 2010). myelination of the nerves, determining both their fitness and their impact on the ecosystem. Body size governs most vital rates and biotic interactions (Kiørboe \& Hirst 2014) and affects marine food webs and carbon fluxes (Turner 2002; García-Comas et al. 2016), feeding mode determines feeding efficiency and associated predation risk (Kiørboe 2011), relative offspring size determines the success in recruitment in a given environment (Neuheimer et al. 2015), and myelination of the nerves is one aspect of predator defense (Lenz 2012) (Box 1).

The aim of this study is to establish large-scale copepod trait biogeographies, including the first ever global analyses. In addition, we tested two hypotheses: (H1) Betweencommunity trait variation is structured in space and time, i.e., trait distributions can be largely described by assuming that they are more similar to neighboring communities than to distant communities. (H2) These spatiotemporally dependent structures form in response to key environmental drivers including food availability, temperature, water transparency, and seasonality, as suggested in Box 1. We combined information on traits for hundreds of marine pelagic copepod taxa with two of the most extensive sets of observational data for 81 copepods, covering the North Atlantic and the global ocean. We demonstrate distinct spatiotemporal trait biogeographies for most traits that can be partly explained by environmental drivers, and partly, such as in the case of differences between ocean basins, as a result of other structuring processes. 


\section{Overview}

The analyses consisted of two steps. Firstly, we combined copepod trait information with field observations of copepod occurrences, defined communities, and summarized those using summary statistics. We combined trait information with two observational datasets with

90 different resolutions in space and time: the North Atlantic with seasonal resolution, and the global ocean without temporal resolution. Secondly, we used statistical models to test our hypotheses, to investigate the spatial/spatiotemporal patterns of trait distributions, and to analyze their relationship with the environment.

\section{Trait data}

Trait data originated from a collection of literature information on functional traits for marine copepods (Brun et al. 2016). Where multiple measurements were available per species, we took species-specific averages. We used body size measurements from adults irrespective of the life stage of the observed individuals and thus estimated an upper boundary of potential body size. In the global analysis, information on mixed feeding was not sufficient to characterize the communities, and we therefore only distinguished between active feeders and passive feeders, considering mixed feeding taxa as active feeders.

\section{Observational data}

Data from the Continuous Plankton Recorder (CPR) survey was used to estimate the spatiotemporal distributions of North Atlantic copepods. The CPR survey is a large-scale 
106 monitoring program of North Atlantic plankton, particularly copepods, diatoms and 107 dinoflagellates (Richardson et al., 2006). The CPR is towed by ships of opportunity at 108 approximately $7 \mathrm{~m}$ depth. Each CPR sample corresponds to 10 nautical miles and around 3

$109 \mathrm{~m}^{3}$ of seawater filtered onto a $270 \mu \mathrm{m}$-sized silk gauze. We used roughly 49000 observations 110 of 67 copepod taxa resolved into abundance classes that have been classified by the CPR 111 survey between 1998 and 2008 (Johns 2014, Appendix A).

112 Observations of CPR taxa were matched with taxon-specific trait estimates. Not all 113 taxa sampled in the CPR were resolved to the species level. Traits for higher order taxa were 114 represented by the traits of the most common species in that group, as reported in Richardson 115 et al. (2006). Where no information about the most common species was available, we 116 averaged traits of all species in the taxon that have been repeatedly observed in the study 117 area, according to the OBIS database (www.iobis.org, Appendix A). Available trait 118 information largely covered the estimated biomass of observed taxa in the North Atlantic 119 (Table 1).

\section{Global}

For the global analysis we used data from the Coastal and Oceanic Plankton Ecology,

122 Production and Observation Database (COPEPOD), which contains abundance information

123 for various plankton groups (O'Brien 2010). This data is compiled from a global collection of 124 cruises, projects, and institutional holdings. Data for copepods consisted of roughly one

125 million observations distributed across the global ocean. We updated the taxonomic 126 classification of the observations according to the most recent online taxonomy 127 (http://www.marinespecies.org/copepoda/) and utilized only data with abundance information 128 and taxonomic resolution at the genus level or higher. In a few cases, we also included pooled 129 observations for two genera, describing their traits based on the first genus mentioned. 
130 Furthermore, we filtered for observations taken in the top 200 meters of the water column and

131 excluded parasitic taxa. While the absolute number of observations lost through the filtering

132 was minor, observations were removed from most of the Pacific, particularly because of

133 lacking taxonomic resolution of data from this area.

Observations were matched with corresponding trait information. Traits at the genus level were estimated as means of the available estimates for their species. For all traits, match-ups were possible for most of the estimated abundance (Table 1). the taxa present. Unlike the CPR data, COPEPOD observations do not have a homogeneous sampling design and no standardized catalogue of taxa was targeted. We therefore split the global ocean into roughly 5000 polygons of similar area, and estimated trait-statistics

141 polygon-wise. For each polygon, we used geometrical means to estimate the relative

142 abundance of each taxon present for which trait information existed.

\section{Summarizing community traits}

144 Community traits were summarized by mass-weighted means and, for body size, also

145 by the Shannon size diversity index. Biomass-weighted means were estimated by using the 146 cubed body length estimates as biomass proxies. In addition, we quantified body-size 147 diversity in copepod communities using the Shannon size diversity index. Body-size diversity 148 characterizes the diversity of size classes within a community, which has been related to 149 food-web properties (García-Comas et al. 2016). Furthermore, it indicates whether copepod 150 communities are affected by environmental filtering. The Shannon size diversity index $(\mu)$ is 151 analogue to the Shannon diversity index but computed on the probability-density function of a continuous-random variable (Quintana et al. 2008). It is estimated as 
where $p_{x}(x)$ represents the probability density function of size $x$. (Quintana et al. 2008). Shannon size diversity was calculated for all polygons with at least 5 observed taxa. The corresponding probability density functions were estimated by weighting the body sizes with the mass fractions of the species present. The Shannon size diversity index is primarily suitable for comparisons between communities.

\section{Environmental data}

Environmental variables considered are proxies for the key factors of temperature, available amount of food, prey size, seasonality, and water transparency (Box 1). For temperature, we used the monthly sea surface temperature (SST) data HadISST1 from the

164 Hadley Centre for Climate Prediction and Research, Meteorological Office (Rayner et al. 165 2003). Available amount of food was characterized with satellite-derived monthly estimates of net primary productivity (NPP) obtained from

167 http://www.science.oregonstate.edu/ocean.productivity based on the VGPM algorithm

168 (Behrenfeld \& Falkowski 1997). Median phytoplankton cell diameter $\left(\mathrm{MD}_{50}\right)$ was used as 169 proxy for prey size, prey motility, and food quality including lipid content. Flagellates of 170 intermediate size typically have a higher motility and lipid content than large-celled diatoms 171 or small bacterioplankton (Kleppel 1993; McManus \& Woodson 2012). Although not all copepods feed solely on phytoplankton, phytoplankton cell size has a strong impact on the entire food web (Barnes et al. 2011). MD $_{50}$ was estimated based on empirical relationships

174 with SST and chlorophyll $a$ concentration (CHL) (Barnes et al. 2011; Boyce et al. 2015), where we used the monthly GlobColour CHL1 product (http://www.globcolour.info/) to 
176 represent CHL. Seasonality manifests itself in various ways including photoperiod,

177 temperature, and available diet. For copepods the most immediate impact of seasonality is

178 arguably the food availability. We therefore characterized seasonality by the seasonal

179 variation in chlorophyll $a$ concentration, applying the Shannon size diversity index on the

180 CHL data (as this index is suitable to estimate the diversity of any non-negative, continuous

181 variable). Water-column transparency was approximated by Secchi Depth (ZSD), represented

182 by the monthly GlobColour ZSD product. For NPP, data from the period 2003-2008 was

183 considered; for all other predictors, the period considered was 1998-2008.

184 Environmental variables were aggregated to match the resolution of the copepod 185 communities. For the North Atlantic analysis we produced $1^{\circ} \times 1^{\circ}$ monthly means for each year for SST, $\mathrm{MD}_{50}$, and ZSD. Since we did not have a complete temporal coverage for NPP, we matched the observations with monthly averages based on the years 2003-2008. CHL seasonality was calculated for each year independently and matched with all months of that year. For the global models, we aggregated the predictors by the polygons used to define the

190 copepod communities, including the entire time-span of data availability. For computational

191 efficiency, and to avoid numerical problems, all environmental variables were discretized to 200 equally-spaced steps, normalized and standardized. Note that particularly on the global scale, some of the predictors showed significant Pearson correlation coefficients $(r)$ up to

$194 r=0.86$ for SST and $\mathrm{MD}_{50}$ (Appendix B). However, the analyses performed here are largely 195 insensitive to collinearity (Dormann et al. 2012).

\section{Statistical modelling}

The integrated nested Laplace approximation (INLA) approach is a novel and computationally-efficient Bayesian statistical tool that is particularly powerful in handling 
199 spatial and spatiotemporal correlation structures (Rue et al. 2009; Blangiardo \& Cameletti 200 2015). We used the INLA approach to model each trait for both observational datasets as a

201 function of i) space (and season), ii) environmental predictors, and iii) as a combination of i) 202 and ii). We modeled the continuous traits (body size, body-size diversity, and relative 203 offspring size) assuming $t$ - and normal-distributions for the North Atlantic and the global 204 models, respectively. The categorical traits (feeding modes and myelination) were modeled assuming beta-binomial and binomial distributions, respectively, both of which require a number-of-trials parameter. For the North Atlantic models we defined the numbers of trials by the total counts of individuals per sample and the number of positives was estimated by

208 the weight fraction of these counts showing the trait in question. In the global models, the 209 number of trials was held constant at one. The fitted models were used to map the trait 210 distributions, investigate the relationships between traits and environmental predictors, and to 211 compare the amount of variance explained by the three model set-ups.

\section{Spatial and spatiotemporal models} Spatial and spatiotemporal models were constructed assuming distributions of traits to

214 have a spatially- and temporally-dependent structure. We assumed trait distributions to be 215 isotropic, stationary Gaussian Fields which are approximated with discrete meshes in INLA 216 (Blangiardo \& Cameletti 2015). We constructed a spatial mesh for each domain and an 217 additional seasonal mesh for the North Atlantic (Appendix C). Furthermore, we 218 complemented the North Atlantic models with a random effect correcting for variations 219 between the years analyzed. 
The environmental modeling approach used is equivalent to ecological niche models, but applied to community properties rather than individual species. For each trait and both observational datasets we fitted models for all possible combinations of the candidate predictors. The predictors were fitted as smooth, non-linear effects using second-order random-walk models (Rue et al. 2009), an approach similar to common generalized additive models (GAMs; Wood 2006) where the non-parametric response form of each predictor is determined by the data. Based on these models we assessed the best predictor combination for each trait according to the minimum Watanabe-Akaike information criterion (WAIC), a modified version of the Akaike Information Criteria that is appropriate for use with mixedeffects models (Gelman et al. 2014). We further used the univariate environmental models to investigate trait-environment relationships: univariate models were chosen over multivariate models to prevent distortions due to collinear predictors (Dormann et al. 2012).

\section{Combined models}

"Combined" models were created by adding spatial/spatiotemporal structures to the best environmental models (Blangiardo \& Cameletti 2015).

\section{Evaluation of hypotheses}

Both of our hypotheses focused on between-community variance of traits. The existence of such variance was confirmed in a preliminary assessment (Appendix D). Hypothesis H1 (community traits are spatially structured) was then tested by quantifying the

240 fraction of variance explained $\left(\mathrm{R}^{2}\right)$ by spatial/spatiotemporal models, and hypothesis $\mathrm{H} 2$

241 (spatial structure is explained by key environmental drivers) was evaluated by comparing the

$242 \mathrm{R}^{2}$ of the best environmental models with the $\mathrm{R}^{2}$ of the combined models. 


\section{Results}

\section{Evaluation of hypotheses}

All traits examined showed distinct structure in space and time, both globally (no 247 temporal resolution) and in the North Atlantic, confirming our hypothesis H1. Our spatial and

248 spatiotemporal models could explain substantial fractions of the between-community trait 249 variance based on the spatial dependency assumption. This was particularly true for global 250 patterns, where $\mathrm{R}^{2}$ of spatial models ranged from 0.36 for active feeding to 0.75 for body size (Figure 1a). In the North Atlantic, the spatiotemporal models were somewhat less efficient for the more finely-resolved communities of the CPR observations and ranged from $\mathrm{R}^{2}=0.32$ for body-size diversity to $\mathrm{R}^{2}=0.48$ for body size (Figure $1 \mathrm{~b}$ ).

Our second hypothesis, that we can explain these spatial patterns with key environmental drivers, proved partially valid. On average, environmental models (green bars in Figure 1c,d) reached approximately half of the $\mathrm{R}^{2}$ of combined models (yellow bars in Figure 1c,d), indicating that about half the patterns in the investigated traits could be explained by the environmental predictors hypothesized to be important. The ratio between

$259 \mathrm{R}^{2}$ for environmental models and $\mathrm{R}^{2}$ for combined models was somewhat higher in the global domain and peaked at $78 \%$ for the global myelination model. Similarly, body size and bodysize diversity could be explained relatively well by the environment, with corresponding

262 percentages well above the $50 \%$ in both domains. For active feeding, on the other hand, 263 environmental models performed relatively poorly and could only explain minor fractions of 264 the identified patterns. 
All traits examined showed seasonally-varying distribution patterns. Mean community

body size varied substantially and mainly ranged between 1 and $5 \mathrm{~mm}$ in the North Atlantic

(Figure 2a-d), corresponding to a two order-of-magnitude variation in body mass.

Communities with the largest mean body size occurred from spring to autumn in the northwestern North Atlantic, in particular in the Labrador Sea (Figure 2b-d). Smallest community-averaged body size was observed in the central and eastern part of the investigated area, mainly during summer (Figure 2c). From spring to autumn, steep spatial gradients in body size existed while the distribution was mostly uniform during winter.

The diversity of body size in copepod communities was estimated to be highest in (Figure 2e). In spring and autumn, body-size diversity was similarly high in the central North Atlantic, but smaller in the coastal areas in the east and the west (Figure 2f,h). Lowest bodysize diversity was found in summer in the entire investigated area, except for the northwestern North Atlantic around the Labrador Sea (Figure 2g).

Active feeding was estimated to be the dominant feeding mode in the North Atlantic. This was particularly true for winter and spring, where, apart from a few exceptions along the coasts, the communities consisted of at least 66\% active feeders (Figure 2i,j). In the eastern part of the investigated area, including the northwestern European coasts, this dominance of active feeders was reduced during summer and autumn and often replaced by a co-dominance of mixed and active feeders (Figure 2k,1). there was considerable spatiotemporal variation. In winter, myelinated and amyelinated 
fractions were roughly in balance, except for the northern central part of the investigated area, where the communities were almost exclusively amyelinated (Figure $2 \mathrm{~m}$ ). The patterns changed markedly in spring when the dominance of myelinated copepods was the greatest, foremost in the northern part of the investigated area (Figure 2n). In summer, and particularly in autumn, the fraction of amyelinated copepods increased again, mainly along the coasts and in the southern and eastern part of the investigated area (Figure 2o,p). the body size of adult females in the North Atlantic. Highest relative offspring size was observed during winter months in the central part of the investigated area (Figure $2 q$ ). In spring, relative offspring size was smaller, in particular in the northwestern North Atlantic, while it gradually increased toward the southeastern part of the investigated area (Figure 2r). In summer and autumn relative offspring size showed a patchy distribution with less variation (Figure 2s,t).

\section{Global trait distributions}

The traits investigated also showed clear spatial patterns on the global scale. Mean body size mainly ranged between 1.5 and $7 \mathrm{~mm}$ for communities observed in the global ocean (polygons in Figure 3). Largest body sizes were found at high latitudes above $50^{\circ}$, except for the North Atlantic where communities with intermediate body size extended somewhat further northward (Figure 3a). According to the best environmental model, the latitudes with the smallest body size were found in the subtropics while around the equator the mean body size was slightly larger. The smallest body sizes were found in the subtropical central Atlantic, 2-3 mm, whereas communities at similar latitudes in the Indian Ocean

311 tended to have larger mean body sizes, around 3-4 mm. Myelination was distributed similarly

312 to body size (pixel to pixel Spearman correlation coefficient, $r_{\text {spearman }}=0.84$ ) but with more 
313 small-scale variation (Figure 3b): at high latitudes myelinated copepods dominated, while at

314 low and intermediate latitudes myelinated and amyelinated taxa were similarly abundant.

315 Again, the central Atlantic differed from the Indian Ocean with a lower fraction of

316 myelinated organisms. Relative offspring size was inversely proportional to body size

$317\left(r_{\text {spearman }}=-0.69\right)$ and myelination $\left(r_{\text {spearman }}=-0.65\right)$. In the global ocean relative egg sizes

318 varied between about 3\% and 8\%, with the relatively largest eggs at low latitudes and the

319 relatively smallest eggs at high latitudes (Figure 3c).

\section{Trait-environment relationships}

Environmental responses of most traits were comparable between the global ocean

Atlantic. Highest body size was found at low NPP, intermediate phytoplankton cell size and

low SST (Figure 4a-c). While globally only intermediate chlorophyll seasonality favored copepod communities with large body size, in the North Atlantic these communities were also found at low CHL seasonality (Figure 4d). Communities with high body-size diversity were most common in environments with low NPP, CHL seasonality and phytoplankton cell size (Figure 4e,f,h). Furthermore, high body-size diversity was found at the high and the low end of the temperature spectrum, while temperatures around $10^{\circ} \mathrm{C}$ were associated with the

330 lowest diversity (Figure 4g). On the global scale, the best model for body-size diversity did not include CHL seasonality. The weight fraction of myelinated copepods was highest in environments with low NPP, and intermediate Secchi Depth (Figure 4i-k). In the global ocean the fraction of myelinated copepods increased with phytoplankton cell size, while in

334 the North Atlantic it peaked at a median cell size of around $6 \mu \mathrm{m}$ and rapidly decreased with 335 larger phytoplankton. Finally, relative offspring size was smallest for low NPP, intermediate 336 phytoplankton cell size and relatively short Secchi Depths of 5-25 m (Figure 4l-n). The best 
337 global model for relative offspring size did not include Secchi Depth. WAIC values for all 338 model combinations of traits and environmental predictors can be seen in Appendix G. 


\section{Discussion}

Our analysis of copepod trait distributions revealed a wealth of strong patterns along

342 several spatial and temporal gradients. Most of these patterns were consistent with the

343 literature or comparable to the trait distributions of other organism groups, yet there were

344 some surprising findings too. Several traits showed considerable latitudinal variation. For

345 example, mean body size was clearly larger at high latitudes than at low latitudes, while it

346 was smallest in the subtropics, and slightly larger around the equator. This pattern is

347 equivalent to the distribution of phytoplankton cell size, and, along the Atlantic Meridional

348 Transect, to the distribution of body size of total zooplankton (San Martin et al. 2006; Boyce

349 et al. 2015). Relative offspring size also changed significantly with latitude and was highest

350 in the subtropics and tropics, paralleling the distribution of seed mass in terrestrial plants

351 (Moles \& Westoby 2003). Trait distributions also showed strong seasonal dynamics. For

352 example, body size in the North Atlantic varied considerably throughout the season with

353 largest copepods in March and April. Similar dynamics have been found for diatoms in the

354 same area, with the largest mean cell size between January and March (Barton et al. 2013a).

355 More unexpected were the clear differences between the central Atlantic and the Indian

356 Ocean found in all traits investigated. This difference was unrelated to the known

357 environmental parameters and has not been found in phytoplankton trait distributions (Barnes 358 et al. 2011).

A substantial fraction of the spatial and temporal patterns could be linked to the

360 environmental predictors investigated. While temperature seemed to affect copepod traits

361 directly, productivity may influence them in more complex ways. It is well established for

362 both terrestrial and aquatic organisms that within species, body size is inversely related to 
temperature (Forster et al. 2012), and this also applies to copepods (Horne et al. 2016). Our results demonstrate that this relationship also holds on the community level. However, body size changed relatively little with increasing temperature when compared to its steep decline with increasing productivity. A negative relationship between body size and productivity is surprising: many groups of marine fish and terrestrial mammals grow larger in areas of higher productivity (Huston \& Wolverton 2011), and the same was found for copepods in laboratory experiments (Berggreen et al. 1988). For copepods in the field this may be different due to size-selective predation by planktivorous fish (Brucet et al. 2010), which are particularly abundant in productive ecosystems like upwelling regions (Cury et al. 2000). Furthermore, in oligotrophic open ocean areas planktonic food chains tend to be longer (Boyce et al. 2015). Thus, although copepods at the same trophic level may be smaller in areas with low productivity, the mean body size of the entire copepod community may be larger. possibly in response to stronger biotic interactions. Large offspring size is often seen as an adaptation to harsh environments (Segers \& Taborsky 2011), and therefore a positive correlation between relative offspring size and productivity may seem surprising at first sight. However, few offspring and comparably high investments in each individual are also characteristics of K-selected species, which live in densely populated communities (MacArthur \& Wilson 1967). In this case, relatively larger offspring may be better in competing for resources and avoiding predation, as has been found for fish: fish fry from

383 large eggs are more tolerant to starvation, avoid predation risks more consequently, and have larger reaction distances to potential predators (Miller et al. 1988; Segers \& Taborsky 2011). 2003). 
About half of the identified spatiotemporal patterns could not be explained by the environmental predictors, but arose from other structuring processes. Some of these unexplained patterns occurred on large spatial scales, where the most-pronounced and surprising differences occurred between the central Atlantic and the Indian Ocean. On these scales evolutionary history may affect trait distributions. The distribution range of copepod species is limited by their ability to maintain viable populations (Norris 2000), although, in principle, water parcels can travel between any pair of locations in the global ocean within a decade (Jönsson \& Watson 2016). Patterns unexplained by the environmental predictors also occurred on smaller spatial scales in the North Atlantic. On these scales other traitenvironment interactions, for example, success in overwintering, may play a role, as well as transportation by ocean currents (Melle et al. 2014). Finally, sampling bias may have caused some unexplained patterns, in particular in the global dataset, where sampling methods and taxonomic detail may have differed somewhat between sampling efforts in different areas. distribution of body size, also provide insight into how copepod communities affect marine ecosystems and carbon fluxes. The distribution of body size in copepod communities has implications for the fate of the primary production, and determines whether it is recycled in the upper ocean, transported to the sea floor via fecal pellets, or channeled toward higher trophic levels. Copepod fecal pellets may contribute a significant but highly variable (0-100 $\%$ ) fraction to the vertical material fluxes in the ocean (Turner 2002), and body size of copepods appears to be the main determinant of this fraction (Stamieszkin et al. 2015): small copepods produce small fecal pellets that are mainly recycled in the upper ocean, while large copepods produce large pellets that rapidly sink to the seafloor. Body-size diversity of 410 mesozooplankton communities, which are typically dominated by copepods (Verity \& 
411 Smetacek 1996), is furthermore positively correlated with the transfer efficiency of primary

412 production to higher trophic levels (García-Comas et al. 2016): the optimal prey size of

413 primary consumers depends on their body size, and therefore communities of primary

414 consumers with diverse body sizes feed efficiently on a range of prey sizes and harvest the

415 phytoplankton communities more exhaustively. Similarly, changes in phyto- and zooplankton

416 community body size composition have been shown to affect the spatial distribution and

417 temporal dynamics of planktivorous fish. In upwelling areas worldwide, spatial distribution

418 and multi-decadal fluctuations of sardine and anchovy stocks have been explained by

419 climate-driven changes in the physical environment and their impact on plankton body size

420 (e.g., Lindegren et al. 2013). Smaller-sized plankton promote filter-feeding fish species with

421 fine gill rakes (e.g., sardine) while larger plankton support particulate-feeders with coarse gill

422 rakes (e.g., anchovy) (van der Lingen et al. 2006).

Focusing on the large-scale spatial and temporal patterns of copepod trait distributions

424 is necessarily crude and ignores conditions specific to certain regions, especially in data-

425 scarce systems like the open ocean. Particularly with our global approach we defined 426 communities in a simplistic way, included some coarse taxonomic groups, and ignored intraspecific variation in continuous traits such as body size. Our observational data were not evenly distributed in the global ocean, and, especially in the Pacific, data with the required quality were largely lacking. Furthermore, our analysis was biased toward large copepods, as 430 it was based on traditional observational data that were mostly taken with mesh sizes of 200 $431 \mu \mathrm{m}$ or coarser (O'Brien 2010). These meshes may not capture one third of the copepod 432 biomass in the small size fractions (Gallienne \& Robins 2001), which is particularly rich in 433 passive feeding taxa like Oithona - a potential explanation for the small fractions of passive 434 feeders we identified in this study (Figure 2, Appendix E). 

traits directly in the field rather than indirectly via taxonomic classification and subsequent merging with trait information from the literature. In-situ imaging may be one way to do so

438 (Picheral et al. 2010). Taking images of plankton communities with cheap, automated 439 devices carried by commercial ships similar to the Continuous Plankton Recorder 440 (Richardson et al. 2006) could greatly speed-up the sampling and improve data coverage. 441 Imaging may be particularly suitable to measure body size compositions (García-Comas et al. 2016), but with the rapid development of algorithm-based image recognition, it may soon be

443 possible to also measure other traits such as sac-spawning or swimming behavior.

Nevertheless, our trait biogeographies showed substantial spatial and temporal structure that was consistently linked to environmental predictors for two independent observational datasets, highlighting the relevance of the trait-based approach to describe

447 copepod biogeography. We demonstrated the value of these biogeographies to test and 448 develop new hypotheses about the drivers of the distribution of zooplankton. Furthermore, 449 our results may be used as a test-bed for trait-based mechanistic models. Ultimately we hope 450 our work will contribute to the development of next generation global models of the 451 dynamics of planktonic ecosystems and their reaction to future climate change. 


\section{Acknowledgements}

455

We acknowledge the Villum foundation for support to the Centre for Ocean Life and

456 the European Union 7th Framework Programme (FP7 2007-2013) under grant agreement

457 number 308299 (NACLIM). Likewise, we wish to thank the many current and retired

458 scientists at SAHFOS whose efforts over the years helped to establish and maintain the

459 Continuous Plankton Recorder survey.

460 


\section{References}

462

463

464

465

466

467

468

469

470

471

472

473

474

475

476

477

478

479

480

481

482

483

484

485

486

487

488

489

490

491

492

493

494

495

496

1.Barnes, C., Irigoien, X., De Oliveira, J.A.A., Maxwell, D. \& Jennings, S. (2011). Predicting marine phytoplankton community size structure from empirical relationships with remotely sensed variables. J. Plankton Res., 33, 13-24.

2.Barton, A.D., Finkel, Z. V., Ward, B. a., Johns, D.G. \& Follows, M.J. (2013a). On the roles of cell size and trophic strategy in North Atlantic diatom and dinoflagellate communities. Limnol. Oceanogr., 58, 254-266.

3.Barton, A.D., Pershing, A.J., Litchman, E., Record, N.R., Edwards, K.F., Finkel, Z. V, et al. (2013b). The biogeography of marine plankton traits. Ecol. Lett., 16, 522-534.

4.Begon, M., Townsend, C.R. \& Harper, J.L. (2006). Ecology: From Individuals to Ecosystems. 4th edn. Blackwell Publishing, Malden, MA.

5.Behrenfeld, M.J. \& Falkowski, P.G. (1997). Photosynthetic rates derived from satellitebased chlorophyll concentration. Limnol. Oceanogr., 42, 1-20.

6.Berggreen, U., Hansen, B. \& Kiørboe, T. (1988). Food size spectra, ingestion and growth of the copepodAcartia tonsa during development: Implications for determination of copepod production. Mar. Biol., 99, 341-352.

7.Blangiardo, M. \& Cameletti, M. (2015). Spatial and Spatio-temporal Bayesian Models with $R$-INLA. 1st edn. Wiley, Chichester, West Sussex, United Kingdom.

8.Boyce, D.G., Frank, K.T. \& Leggett, W.C. (2015). From mice to elephants: overturning the "one size fits all" paradigm in marine plankton food chains. Ecol. Lett., 18, 504-515.

9.Brix, H., Menemenlis, D., Hill, C., Dutkiewicz, S., Jahn, O., Wang, D., et al. (2015). Using Green's Functions to initialize and adjust a global, eddying ocean biogeochemistry general circulation model. Ocean Model., 95, 1-14.

10.Brucet, S., Boix, D., Quintana, X.D., Jensen, E., Nathansen, L.W., Trochine, C., et al. (2010). Factors influencing zooplankton size structure at contrasting temperatures in coastal shallow lakes: Implications for effects of climate change. Limnol. Oceanogr., 55, 1697-1711. 
498 11.Brun, P., Payne, M.R. \& Kiørboe, T. (2016). A trait database for marine copepods. Earth 499 Syst. Sci. Data Discuss., 1-33.

500

501

502

503

504

505

506

507

508

509

510

511

512

513

514

515

516

517

518

519

520

521

522

523

524

525

526

527

528

529

530

531

532

533

12.Cury, P., Bakun, A., Crawford, R.J.M., Jarre, A., Quinones, R.A., Shannon, L.J., et al. (2000). Small pelagics in upwelling systems: patterns of interaction and structural changes in "wasp-waist" ecosystems. ICES J. Mar. Sci., 57, 603-618.

13.Dormann, C.F., Elith, J., Bacher, S., Buchmann, C., Carl, G., Carré, G., et al. (2012). Collinearity: a review of methods to deal with it and a simulation study evaluating their performance. Ecography (Cop.)., 36, 27-46.

14.Edwards, K.F., Litchman, E. \& Klausmeier, C.A. (2013). Functional traits explain phytoplankton community structure and seasonal dynamics in a marine ecosystem. Ecol. Lett., 16, 56-63.

15.Elith, J. \& Leathwick, J.R. (2009). Species Distribution Models: Ecological Explanation and Prediction Across Space and Time. Annu. Rev. Ecol. Evol. Syst., 40, 677-697.

16.Forster, J., Hirst, A.G. \& Atkinson, D. (2012). Warming-induced reductions in body size are greater in aquatic than terrestrial species. Proc. Natl. Acad. Sci. U. S. A., 109, 19310-4.

17.Gallienne, C.P. \& Robins, B.D. (2001). Is Oithona the most important copepod in the world's oceans? J. Plankton Res., 23, 1421-1432.

18.García-Comas, C., Sastri, A.R., Ye, L., Chang, C., Lin, F., Su, M., et al. (2016). Prey size diversity hinders biomass trophic transfer and predator size diversity promotes it in planktonic communities. Proc. R. Soc. B Biol. Sci., 283, 20152129.

19.Gelman, A., Hwang, J. \& Vehtari, A. (2014). Understanding predictive information criteria for Bayesian models. Stat. Comput., 24, 997-1016.

20.Hansen, B., Bjørnsen, P.K. \& Hansen, P.J. (1994). The size ratio between planktonic predators and their prey. Limnol. Oceanogr., 39, 395-403.

21.Hopcroft, R.R., Roff, J.C. \& Chavez, F.P. (2001). Size paradigms in copepod communities: a re-examination. Hydrobiologia, 453/454, 133-141. 
22.Horne, C.R., Hirst, A.G., Atkinson, D., Neves, A. \& Kiørboe, T. (2016). A global synthesis of seasonal temperature-size responses in copepods. Glob. Ecol. Biogeogr., 1-12.

23.Huston, M.A. \& Wolverton, S. (2011). Regulation of animal size by eNPP, Bergmann's rule, and related phenomena. Ecol. Monogr., 81, 349-405.

24.Johns, D.G. (2014). Raw data for copepods in the North Atlantic (25-73N, 80W-20E) 1998-2008 as recorded by the Continuous Plankton recorder. Doi: 10.7487/2014.344.1.138

25.Jönsson, B.F. \& Watson, J.R. (2016). The timescales of global surface-ocean connectivity. Nat. Commun., 7, 11239.

26.Keith, S.A., Webb, T.J., Bohning-Gaese, K., Connolly, S.R., Dulvy, N.K., Eigenbrod, F., et al. (2012). What is macroecology? Biol. Lett., 8, 904-906.

27.Kiørboe, T. (2011). How zooplankton feed: mechanisms, traits and trade-offs. Biol. Rev., 86, 311-339.

27.Kiørboe, T. (2011). How zooplankton feed: Mechanisms, traits and trade-offs. Biol. Rev.

28.Kiørboe, T. (2013). Attack or Attacked: The Sensory and Fluid Mechanical Constraints of Copepods' Predator-Prey Interactions. Integr. Comp. Biol., 53, 821-831.

29.Kiørboe, T. \& Hirst, A.G. (2014). Shifts in Mass Scaling of Respiration, Feeding, and Growth Rates across Life-Form Transitions in Marine Pelagic Organisms. Am. Nat., 183, E118-E130.

30.Kleppel, G. (1993). On the diets of calanoid copepods. Mar. Ecol. Prog. Ser., 99, 183195.

31.Lenz, P.H. (2012). The biogeography and ecology of myelin in marine copepods. J. Plankton Res., 34, 575-589. 
33.van der Lingen, C., Hutchings, L. \& Field, J. (2006). Comparative trophodynamics of anchovy Engraulis encrasicolus and sardine Sardinops sagax in the southern Benguela: are species alternations between small pelagic fish trophodynamically mediated? African J. Mar. Sci., 28, 465-477.

576

577

578

579

580

581

582

583

584

585

586

587

588

589

590

591

592

593

594

595

596

597

598

599

600

601

602

603

604

605

606

607

608

609

610

34.Litchman, E., Ohman, M.D. \& Kiørboe, T. (2013). Trait-based approaches to zooplankton communities. J. Plankton Res., 35, 473-484.

35.MacArthur, R. \& Wilson, E.O. (1967). The Theory of Island Biogeography. Theory Isl. Biogeogr. Princeton University Press.

36.McManus, M.A. \& Woodson, C.B. (2012). Plankton distribution and ocean dispersal. J. Exp. Biol., 215, 1008-16.

37.Melle, W., Runge, J., Head, E., Plourde, S., Castellani, C., Licandro, P., et al. (2014). The North Atlantic Ocean as habitat for Calanus finmarchicus: Environmental factors and life history traits. Prog. Oceanogr., 129, 244-284.

38.Miller, T.J., Crowder, L.B., Rice, J. a. \& Marschall, E. a. (1988). Larval Size and Recruitment Mechanisms in Fishes: Toward a Conceptual Framework. Can. J. Fish. Aquat. Sci., 45, 1657-1670.

39.Moles, A.T. \& Westoby, M. (2003). Latitude, seed predation and seed mass. J. Biogeogr., $30,105-128$.

40.Neuheimer, A.B., Hartvig, M., Heuschele, J., Hylander, S., Kiørboe, T., Olsson, K.H., et al. (2015). Adult and offspring size in the ocean over 17 orders of magnitude follows two life history strategies. Ecology, 96, 3303-3311.

41.Norris, R.D. (2000). Pelagic species diversity, biogeography, and evolution. Paleobiology, 26, 236-258.

42.O'Brien, T.D. (2010). COPEPOD: The Global Plankton Database. An overview of the 2010 database contents, processing methods, and access interface. US Dep. Commerce, NOAA Tech. Memo NMFS-F/ST-36, 28 pp.

43.Picheral, M., Guidi, L., Stemmann, L., Karl, D.M., Iddaoud, G. \& Gorsky, G. (2010). The Underwater Vision Profiler 5: An advanced instrument for high spatial resolution studies of particle size spectra and zooplankton. Limnol. Oceanogr. Methods, 8, 462-473. 
612 44.Quintana, X.D., Brucet, S., Boix, D., López-Flores, R., Gascón, S., Badosa, A., et al. 613 (2008). A nonparametric method for the measurement of size diversity with emphasis on data 614 standardization. Limnol. Oceanogr. Methods, 6, 75-86.

615

616

617

618

619

620

621

622

623

624

625

626

627

628

629

630

631

632

633

634

635

636

637

638

639

640

641

642

643

644

645

646

647

648
45.Rayner, N.A., Parker, D.E., Horton, E.B., Folland, C.K., Alexander, L. V., Rowell, D.P., et al. (2003). Global analyses of sea surface temperature, sea ice, and night marine air temperature since the late nineteenth century. J. Geophys. Res., 108, 4407.

46.Richardson, A.J., Walne, A.W., John, A.W.G., Jonas, T.D., Lindley, J. a., Sims, D.W., et al. (2006). Using continuous plankton recorder data. Prog. Oceanogr., 68, $27-74$.

47.Rue, H., Martino, S. \& Chopin, N. (2009). Approximate Bayesian inference for latent Gaussian models by using integrated nested Laplace approximations. J. R. Stat. Soc. Ser. B (Statistical Methodol., 71, 319-392.

48.San Martin, E., Harris, R.P. \& Irigoien, X. (2006). Latitudinal variation in plankton size spectra in the Atlantic Ocean. Deep Sea Res. Part II Top. Stud. Oceanogr., 53, 1560-1572.

49.Scheiter, S., Langan, L. \& Higgins, S.I. (2013). Next-generation dynamic global vegetation models: learning from community ecology. New Phytol., 198, 957-969.

50.Segers, F.H.I.D. \& Taborsky, B. (2011). Egg size and food abundance interactively affect juvenile growth and behaviour. Funct. Ecol., 25, 166-176.

51.Stamieszkin, K., Pershing, A.J., Record, N.R., Pilskaln, C.H., Dam, H.G. \& Feinberg, L.R. (2015). Size as the master trait in modeled copepod fecal pellet carbon flux. Limnol. Oceanogr., 60, 2090-2107.

52.Turner, J. (2002). Zooplankton fecal pellets, marine snow and sinking phytoplankton blooms. Aquat. Microb. Ecol., 27, 57-102.

53.Verity, P. \& Smetacek, V. (1996). Organism life cycles, predation, and the structure of marine pelagic ecosystems. Mar. Ecol. Prog. Ser., 130, 277-293.

54.Westoby, M., Falster, D.S., Moles, A.T., Vesk, P.A. \& Wright, I.J. (2002). Plant Ecological Strategies: Some Leading Dimensions of Variation Between Species. Annu. Rev. Ecol. Syst., 33, 125-159. 
650 55.Wood, S. (2006). Generalized Additive Models: An Introduction with R. CRC Press, Boca 651 Raton, Florida.

652 


\section{Tables}

Table 1: Trait data coverage for taxa included in observational datasets: covered

655 fractions of taxonomic diversity and biomass/abundance are shown for the North Atlantic and

656 the global ocean. Biomass fractions could be estimated for the North Atlantic using cubed

657 total length as mass proxies, since data on total length was available for all taxa. For the

658 global ocean this was not the case and we therefore report percentages of abundance (number

659 of individuals). North Atlantic data stems from the Continuous Plankton Recorder; global

660 data stems from the Coastal and Oceanic Plankton Ecology, Production and Observation

661 Database.

\begin{tabular}{lcccc}
\hline \multirow{2}{*}{ Trait } & \multicolumn{2}{c}{$\begin{array}{c}\text { North Atlantic (67 taxa) } \\
\text { Diversity }\end{array}$} & Biomass & Global (607 taxa) \\
& $100 \%$ & $100 \%$ & $95 \%$ & $99 \%$ \\
\hline Body size & $99 \%$ & $100 \%$ & $78 \%$ & $96 \%$ \\
Feeding mode & $100 \%$ & $100 \%$ & $100 \%$ & $100 \%$ \\
Myelination & $55 \%$ & $99 \%$ & $23 \%$ & $70 \%$ \\
Relative offspring size & & & & Abundance \\
\hline
\end{tabular}

662 
Figure 1: Fraction of variance explained by INLA models for each trait based on

665

666

667

668

669

670

671

672

673

674

675

676

677

678

679

680

681

682

683

684

spatial/spatiotemporal predictors (red), environmental predictors (green), and both types of predictors (yellow). Results are shown for global models (left panels) and North Atlantic models (right panels). Combined and environmental models for the North Atlantic were run on a subset of the observations used for the spatiotemporal models due to missing environmental data (satellite observations during winter months). $\mathrm{R}^{2}$ of spatiotemporal models can thus be slightly higher than corresponding $\mathrm{R}^{2}$ combined models.

Figure 2: Seasonal succession of community traits in the North Atlantic 1998-2008.

Estimated trait distributions are shown for the beginning of January, April, July, and October (columns) for body size, body-size diversity, feeding modes, myelination and relative offspring size (columns). Displayed are only pixels with a maximum distance of 400 kilometers from observations in every season. Estimates of spatial and temporal autocorrelation of trait distributions in the North Atlantic are shown in Appendix F.

Figure 3: Global distributions of community mean traits for body size (a), myelination (b), and relative offspring size (c). Polygons on the maps represent simulated communities. Colored polygons are data-based estimates; polygons in gray scales are predictions with the best environmental models. The panels on the right show trait distributions per latitude. Median model predictions (lines) and 90\% confidence intervals (polygons) are shown in grey. Data-based trait patterns are superimposed in orange, including median (circles), inter quartile range (thick lines), and 90\% confidence intervals (thin lines). Global maps for further traits can be seen in Appendix E. Estimates of spatial autocorrelation lengths of global trait distributions are shown in Appendix F. 
687 importance based on single-predictor models. Traits include body size, body-size diversity, 688 myelinated fraction, and relative offspring size (rows). Responses for fractional traits are 689 shown on the logit scale. Environmental predictors are net primary production (left row), 690 phytoplankton cell diameter (second row from left), sea surface temperature (second row 691 from right), seasonality of chlorophyll $a$ concentration (right row top), and Secchi Depth 692 (right row bottom). Lines in dark blue represent global models, lines in cyan represent North 693 Atlantic models. Shaded areas surrounding the lines illustrate 95\% confidence intervals. 694 Dashed lines represent predictors not included in the best environmental models of the 695 corresponding trait and domain. Responses for active feeding are shown in Appendix $\mathrm{H}$. 
Figure 1
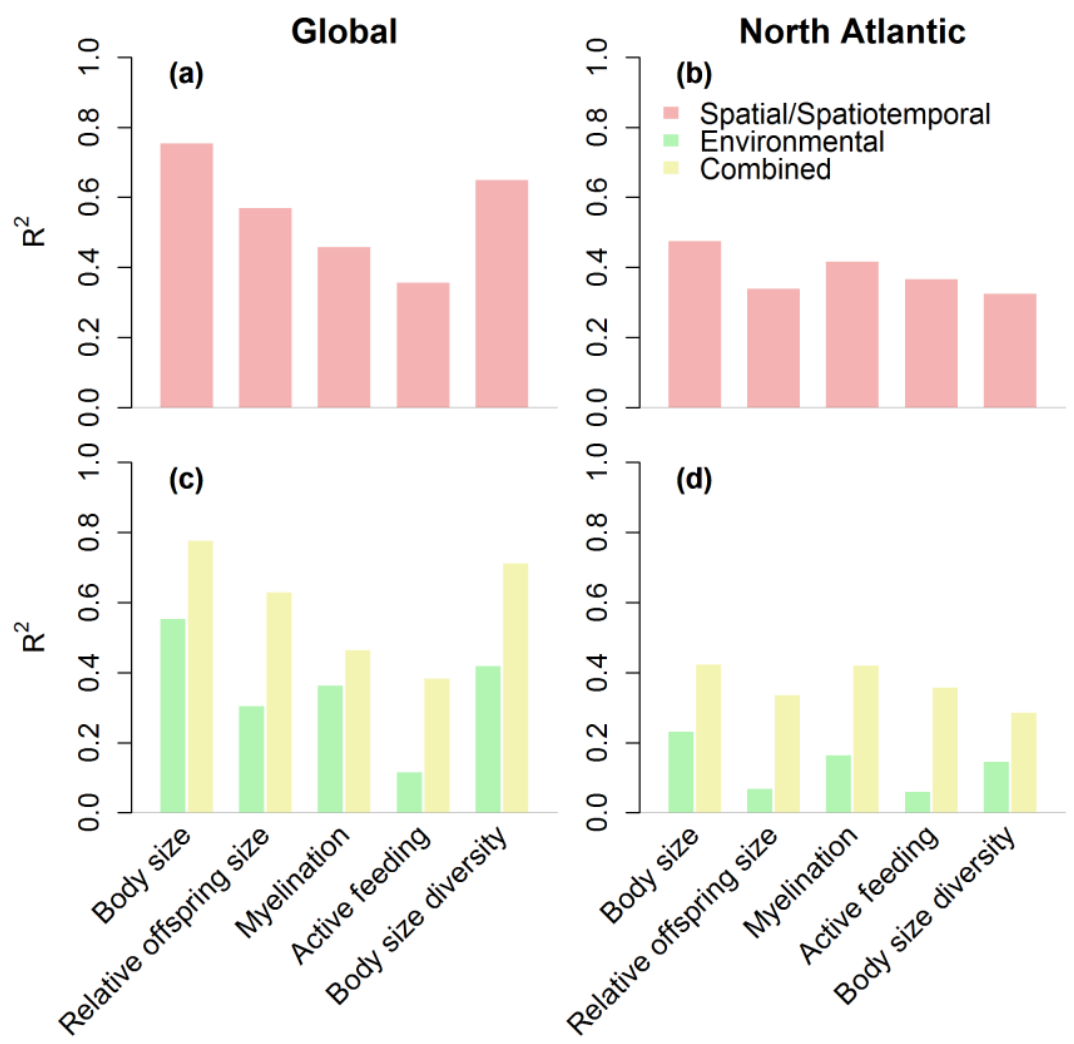

699 

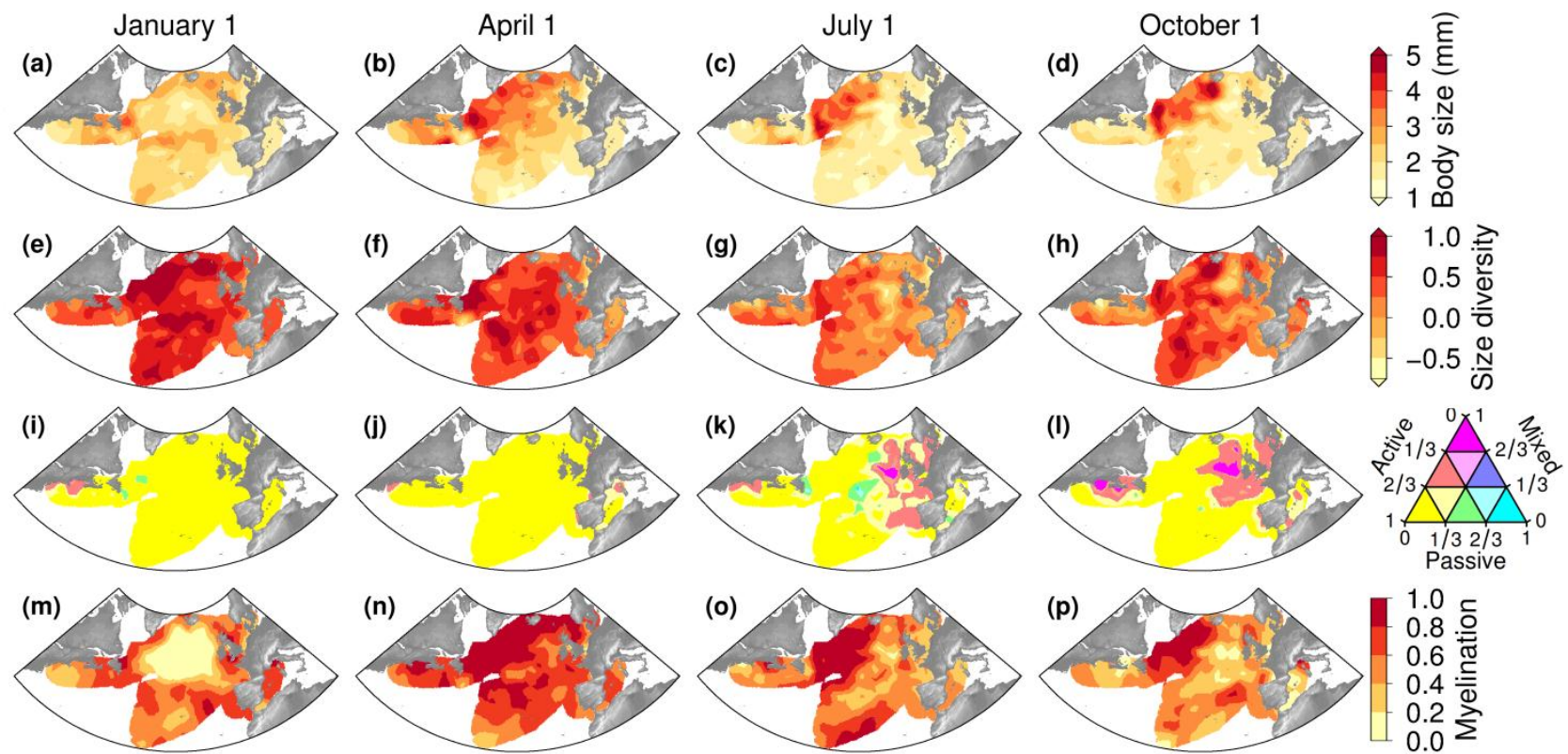

(q)

(r)

(s)

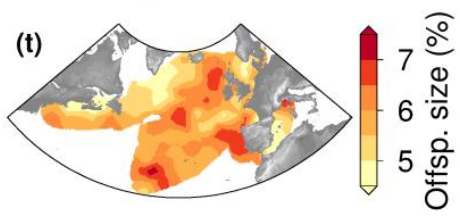

702
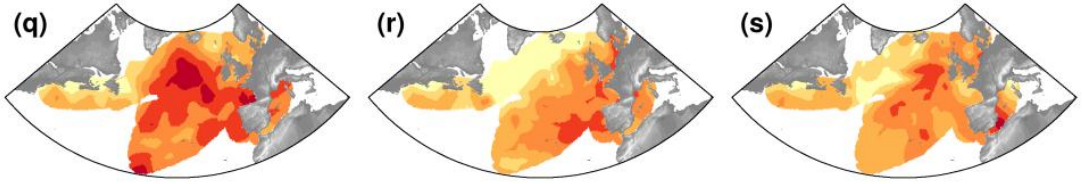

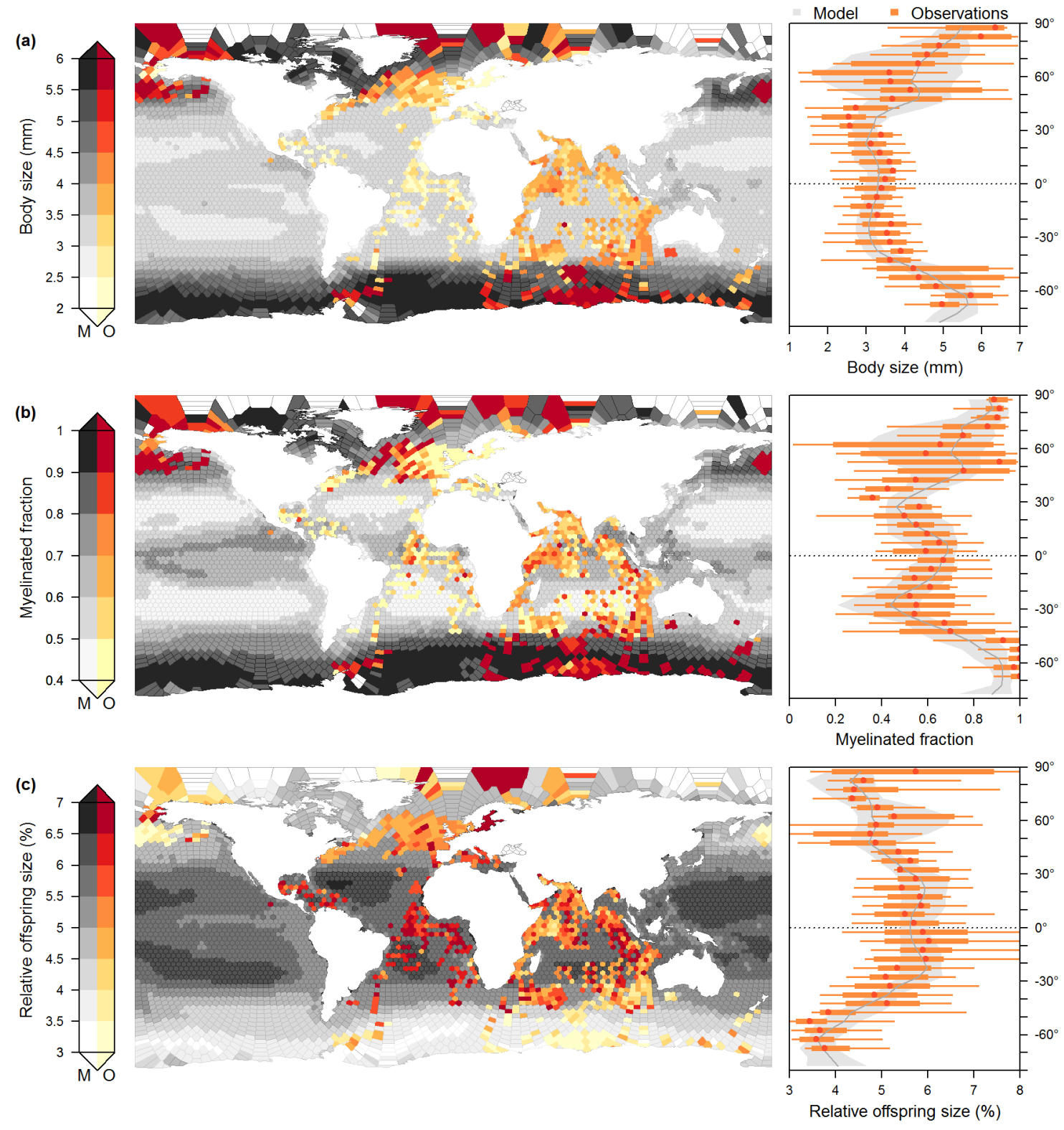

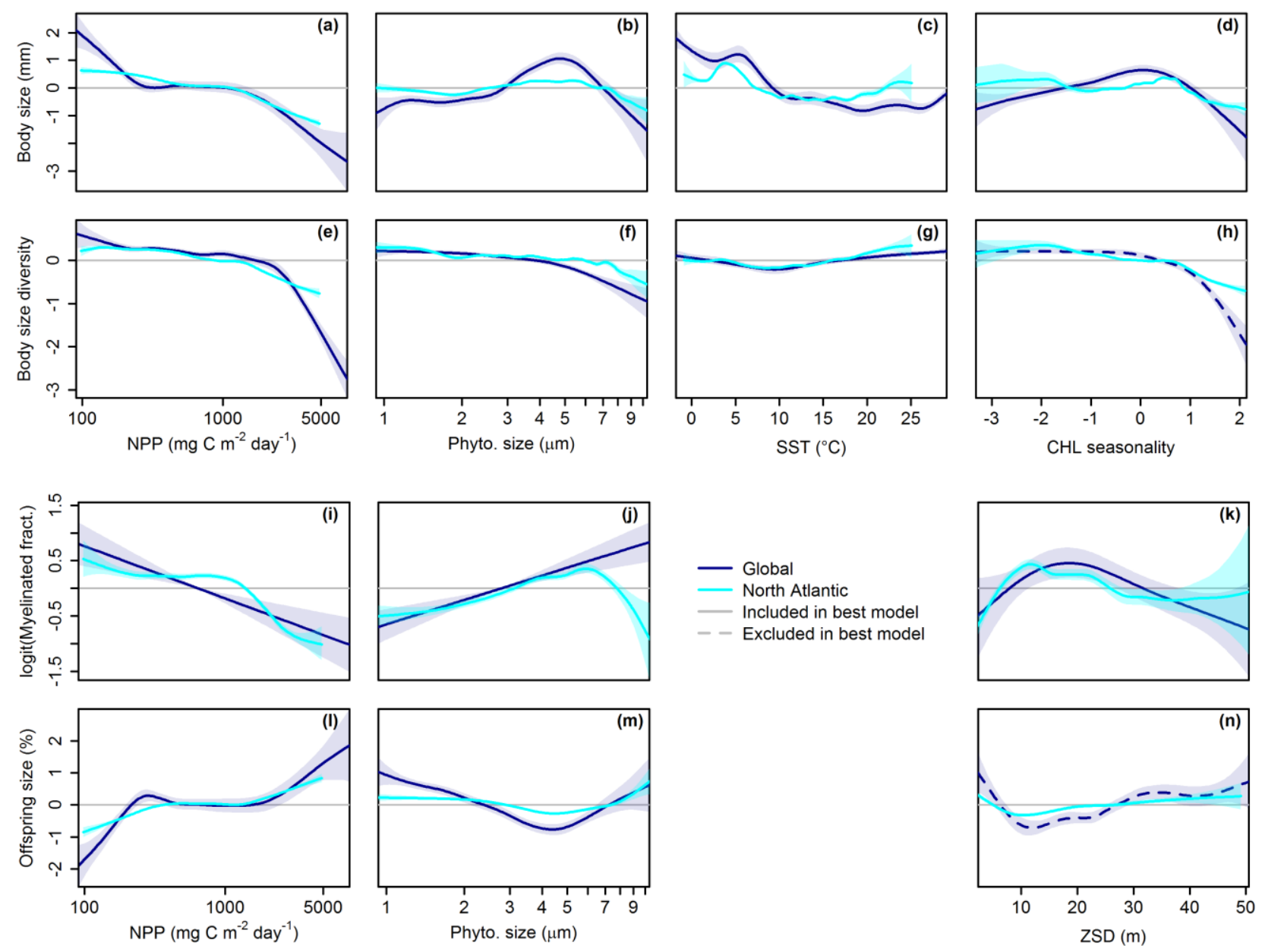
711 Box1: Traits considered and their hypothesized dependence on the environment

712 Body size

Body size is a master trait affecting all major life missions of an organism, i.e.,

714 feeding, survival, and reproduction (Litchman et al. 2013). It can be considered a proxy for

715 several other essential properties such as most vital rates, mobility, and prey size. Here, body

716 size is represented by the total length of adults. We hypothesize that mean body size in

717 copepod communities decreases with increasing temperatures. Such a relationship is known

718 to occur within copepod species, potentially due to oxygen limitation of large organisms at

719 warm temperatures (Forster et al. 2012). Furthermore, we expect copepod body size to be

720 positively correlated to productivity, as has been shown for many animal groups (Huston \&

721 Wolverton 2011). Larger body size has also been shown to be beneficial for copepods to cope with seasonal environments (Maps et al. 2014), and we thus expect body size to be positively related to the intensity of the seasonal cycle. Finally, we hypothesize that copepod body size is positively related to the size of the local prey, as feeding efficiency in copepods is a function of the predator to prey size ratio (Hansen et al. 1994).

Feeding mode

We distinguish between three different feeding modes: passive feeding, active feeding, and mixed feeding (Kiørboe 2011). Passive feeding includes mainly ambush feeding but also particle feeding copepods. The former copepods wait for prey to pass within their perceptive range, while the latter feed on large particles of marine snow. Active strategies comprise cruise feeding and feeding current feeding, where the copepod either moves 
732 through the water or generates a feeding current. Most taxa exclusively use either an active or

733 a passive feeding behavior, but some taxa are able to alternate (called mixed feeders in this

734 paper). Ambush feeders rely on motile prey for feeding and therefore we hypothesize that

735 passive feeders are more common in areas with more motile phytoplankton like flagellates.

736 Furthermore, we expect passive feeders to be less common in unproductive areas as they

737 have lower feeding rates (Kiørboe 2013) and may struggle more with low prey

738 concentrations. Lastly, we hypothesize mixed feeding to be a trait that is beneficial in

739 seasonal environments with varying prey types and concentrations.

$740 \quad$ Relative offspring size

741 Some copepod species have relatively larger (and fewer) eggs than others, suggesting

742 differences in the investment made per offspring. We estimate these differences as relative

743 offspring size, the ratio between egg diameter and the length of the adult female. We do not

744 study absolute egg diameters here, as they scale positively with body size (Neuheimer et al.

745 2015): according to our data the corresponding Pearson correlation coefficient is $r=0.84$

746 ( $n=166)$, while $r$ for relative offspring size versus body size is $-0.19(n=164)$. We expect large

747 relative offspring size to be beneficial in harsh environments (Segers \& Taborsky 2011) with

748 low productivity, low quality of food but also low predation pressure.

749 Myelination

750 Copepods can be grouped into myelinated and amyelinated taxa (Lenz 2012). Myelin

751 is a membranous sheath that surrounds the axons of neurons and greatly enhances the speed

752 of signal transmission. Myelinated copepods are more efficient in escaping predators and

753 need less energy to maintain their nervous systems, but they rely on a more lipid-rich diet 
754 (Lenz 2012). We hypothesize that myelination to common in areas where predation pressure

755 is high, where productivity is low, and where food quality is high (Lenz 2012). 
which traits were estimated.

\begin{tabular}{|c|c|}
\hline CPR taxon & Species considered for trait estimate \\
\hline Acartia spp. (unidentified) ${ }^{\mathrm{a}}$ & A. clausi \\
\hline Acartia danae & A. danae \\
\hline Acartia longiremis & A. longiremis \\
\hline Aetideus armatus & A. armatus \\
\hline Anomalocera patersoni & A. patersoni \\
\hline Calanoides carinatus & C. carinatus \\
\hline Calanus finmarchicus & C. finmarchicus \\
\hline Calanus glacialis & C. glacialis \\
\hline Calanus helgolandicus & C. helgolandicus \\
\hline Calanus hyperboreus & C. hyperboreus \\
\hline Calocalanus spp. ${ }^{\mathrm{b}}$ & C. contractus, $C$. pavo, $C$. plumulosus, $C$. styliremis, $C$. tenuis \\
\hline Candacia armata & C. armata \\
\hline Candacia ethiopica & C. ethiopica \\
\hline Candacia pachydactyla & C. pachydactyla \\
\hline Paracandacia simplex & C. simplex \\
\hline Centropages bradyi & C. bradyi \\
\hline $\begin{array}{l}\text { Centropages chierchiae } \\
\text { eyecount }\end{array}$ & C. chierchiae \\
\hline Centropages hamatus & C. hamatus \\
\hline Centropages typicus & C. typicus \\
\hline Centropages violaceus & C. violaceus \\
\hline Clausocalanus spp. ${ }^{\mathrm{b}}$ & C. arcuicornis, $C$. furcatus, $C$. paululus, C. pergens \\
\hline Corycaeus spp. ${ }^{\mathrm{a}, \mathrm{b}}$ & C. speciosus, Ditrichocorycaeus anglicus \\
\hline Ctenocalanus vanus & C. vanus \\
\hline Eucalanus spp. ${ }^{\mathrm{b}}$ (Unidentified) & E. elongatus, Pareucalanus attenuatus \\
\hline Eucalanus hyalinus & E. hyalinus \\
\hline Euchaeta acuta & E. acuta \\
\hline Euchaeta marina & E. marina \\
\hline Euchirella rostrata & E. rostrata \\
\hline Heterorhabdus norvegicus & H. norvegicus \\
\hline Heterorhabdus papilliger & H. papilliger \\
\hline Isias clavipes & I. clavipes \\
\hline Labidocera spp. $^{\mathrm{b}}$ (Unidentified) & L. acutifrons, L. aestiva, L. wollastoni \\
\hline 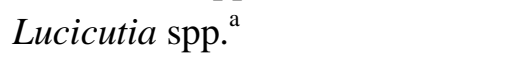 & L. flavicornis \\
\hline Mecynocera clausi & M. clausi \\
\hline Mesocalanus tenuicornis & M. tenuicornis \\
\hline
\end{tabular}




\begin{tabular}{|c|c|}
\hline Metridia longa & M. longa \\
\hline Metridia lucens & M. lucens \\
\hline Harpacticoida Total Traverse $\mathrm{a}^{\mathrm{a} b}$ & Microsetella norvegica, Microsetella rosea \\
\hline Nannocalanus minor & N. minor \\
\hline Neocalanus gracilis & N. gracilis \\
\hline Oithona spp. ${ }^{\mathrm{b}}$ & $\begin{array}{l}\text { O. atlantica, } O \text {. linearis, } O . \text { nana, } O \text {. plumifera, } O \text {. robusta, } O \text {. } \\
\text { setigera, } O \text {. similis }\end{array}$ \\
\hline Oncaea spp. ${ }^{\mathrm{b}}$ & $\begin{array}{l}\text { O. media, O. mediterranea, O. ornata, O. venusta } \\
\text { Paracalanus parvus, Pseudocalanus elongatus, Pseudocalanus }\end{array}$ \\
\hline Para-Pseudocalanus spp. ${ }^{\mathrm{b}}$ & minutus \\
\hline Paracandacia bispinosa & P. bispinosa \\
\hline Paraeuchaeta gracilis & P. gracilis \\
\hline Paraeuchaeta hebes & P. hebes \\
\hline Paraeuchaeta norvegica & P. norvegica \\
\hline Parapontella brevicornis & P. brevicornis \\
\hline Pleuromamma abdominalis & P. abdominalis, $P$. indica \\
\hline Pleuromamma borealis & P. borealis \\
\hline Pleuromamma gracilis & P. gracilis \\
\hline Pleuromamma piseki & P. piseki \\
\hline Pleuromamma robusta & P. robusta \\
\hline Pleuromamma xiphias & P. xiphias \\
\hline Pontellina plumata & P. plumata \\
\hline Scolecithricella spp. ${ }^{\mathrm{b}}$ & P. ovata, S. dentata, S. minor, S. vittata \\
\hline Rhincalanus nasutus & R. nasutus \\
\hline Scolecithrix danae & S. danae \\
\hline Subeucalanus crassus & S. crassus \\
\hline Subeucalanus monachus & S. monachus \\
\hline Temora longicornis & T. longicornis \\
\hline Temora stylifera & T. stylifera \\
\hline Tortanus discaudatus & T. discaudatus \\
\hline Undeuchaeta major & U. major \\
\hline Undeuchaeta plumosa & U. plumosa \\
\hline Undinula vulgaris & U.vulgaris \\
\hline Urocorycaeus spp. ${ }^{\mathrm{b}}$ & U. furcifer, $U$. lautus, $U$. longistylis \\
\hline
\end{tabular}

$759{ }^{\mathrm{a}}$ Most common species in taxon according to (Richardson et al. 2006) was considered for trait information.

$760{ }^{\mathrm{b}}$ Trait estimates for genus based on arithmetic mean of species common in the North Atlantic according to 761 www.iobis.org. 


\section{Appendix B: Correlation analysis of environmental}

764 variables

Pearson correlation coefficients between all pairs of environmental predictors used:

766 values in italic indicate correlation coefficients for observations in the North Atlantic; non-

767 italic values indicate values on the global scale. Grey color represents variable combinations

768 which are never used in the models (ZSD and CHL seasonality). Fields highlighted in yellow

769 represent combinations used in the models with correlation coefficients higher than 0.7 .

\begin{tabular}{|c|c|c|c|c|c|}
\hline & $\mathbf{S S T}^{\mathbf{a}}$ & ZSD $^{\mathbf{b}}$ & $\mathbf{N P P}^{\mathrm{c}}$ & CHL seasonality ${ }^{d}$ & $\mathrm{MD}_{50}^{\mathrm{e}}$ \\
\hline \multirow{2}{*}{ SST } & 1 & 0.47 & -0.06 & -0.52 & -0.86 \\
\hline & 1 & 0.48 & -0.15 & -0.49 & -0.58 \\
\hline \multirow{2}{*}{ ZSD } & 0.47 & 1 & -0.78 & -0.92 & -0.82 \\
\hline & 0.48 & 1 & -061 & -0.6 & -0.79 \\
\hline \multirow{2}{*}{ NPP } & -0.06 & -0.78 & 1 & 0.77 & 0.5 \\
\hline & -0.15 & -0.61 & 1 & 0.37 & 0.4 \\
\hline \multirow{2}{*}{ CHL seasonality } & -0.52 & -0.92 & 0.77 & 1 & 0.86 \\
\hline & -0.49 & -0.6 & 0.37 & 1 & 0.59 \\
\hline \multirow{2}{*}{$\mathbf{M D}_{\mathbf{5 0}}$} & -0.86 & -0.82 & 0.5 & 0.86 & 1 \\
\hline & -0.58 & -0.79 & 0.42 & 0.59 & 1 \\
\hline
\end{tabular}

$770 \quad{ }^{\mathrm{a}}$ Sea surface temperature; ${ }^{\mathrm{b}}$ Secchi Depth; ${ }^{\mathrm{c}}$ net primary productivity; ${ }^{\mathrm{d}}$ seasonality in chlorophyll $a$ concentrations;

771 e median diameter of phytoplankton cells 


\section{Appendix C: Spatial and temporal meshes for INLA}

774

775

776

777

778

779

780

781

782

783

784

785

786

787

788

789

\section{North Atlantic}

Models for the North Atlantic were constructed including both, a spatial and a seasonal mesh. The spatial mesh covered the North Atlantic and was constrained by the coastlines (islands with an area smaller than $100000 \mathrm{~km}^{2}$ were ignored). The maximum distance between mesh points was chosen to be about $300 \mathrm{~km}$ (Figure C1). The seasonal mesh had nodes at the beginning of January, April, July, and October and was cyclic at its boundaries.

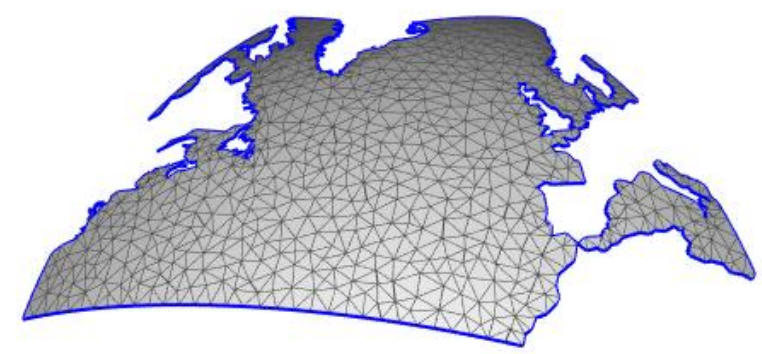

Figure C1: Delaunay triangulation of the North Atlantic domain. Points (intersections) of the field are used to estimate the spatial dependencies in INLA models. We projected the coordinates onto a sphere in order to realistically represent the spatial distances.

\section{Global}

Spatial models of global trait distributions were modeled based on a spherical, global mesh defined with a maximum distance of about $500 \mathrm{~km}$ between the points and constrained by coarse continental borders (again, islands with an area smaller than $100000 \mathrm{~km}^{2}$ were ignored) (Figure C2). 


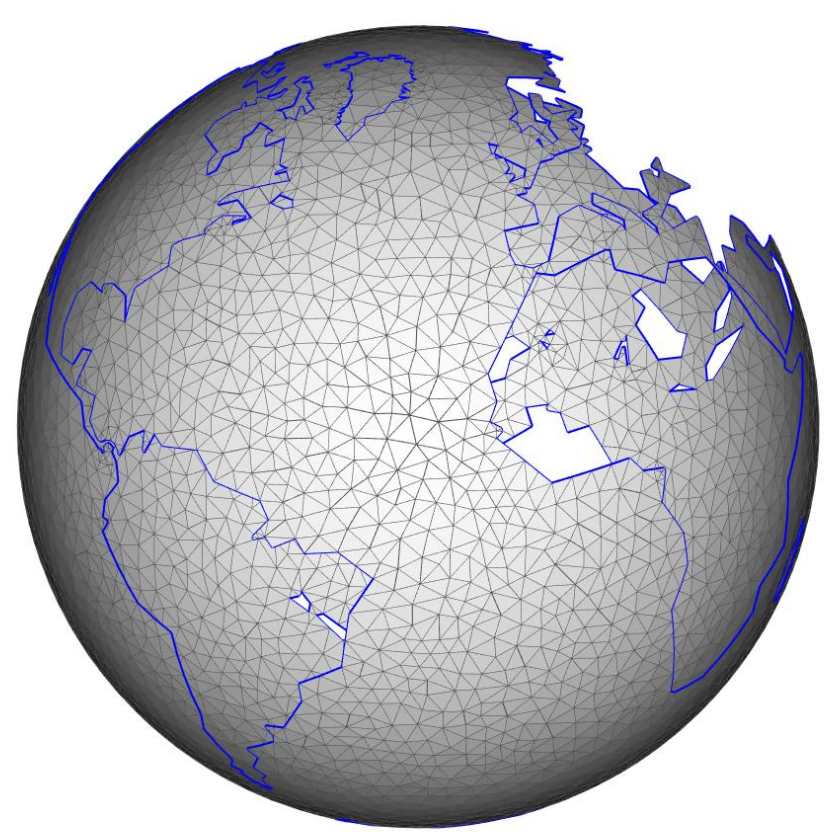

791

792

Figure C2: Delaunay triangulation of the global domain. Points (intersections) of the

793 field are used to estimate the spatial dependencies in INLA models. We projected the

794 coordinates onto a sphere in order to realistically represent the spatial distances.

795

796 


\section{Appendix D: Verification of the existence of between-}

We found clear variation between communities in all traits of both the North Atlantic

800 and the global domain. The existence of variation was assessed using a bootstrapping

801 approach on the variance of the summary statistics (see Methods). We tested whether the

802 variance among communities of these summary statistics differed from zero. To this end we

803 resampled each summary statistic in of both domains 1000 times with replacement. For each

804 of these 1000 pseudo-samples of communities we then calculated the variance. The histograms for these variances are shown in Figure D1. For all traits and both domains we could clearly confirm our hypothesis that a significant variation of traits exists between copepod communities.

808
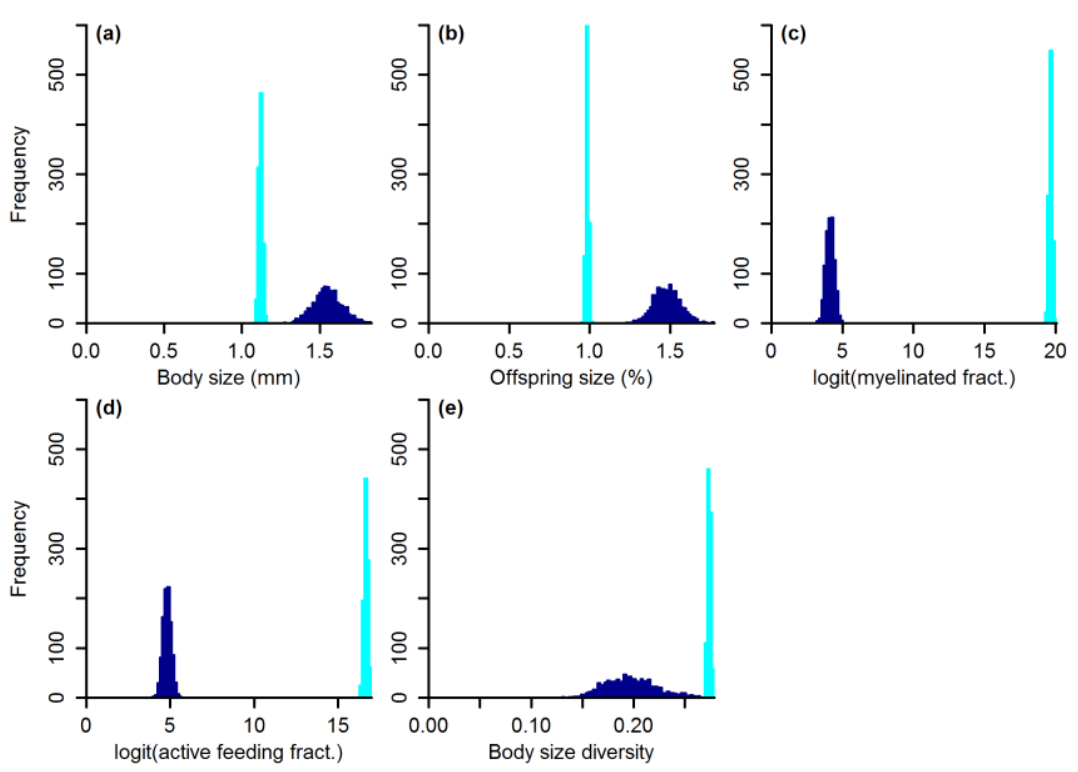

Figure D1: Histograms of standard deviations for body size (a), relative offspring size

810 (b), the logit transformed fraction of myelinated copepods (c), the logit transformed fraction

811 of active feeding copepods (d), and body-size diversity (e). Variance estimates for the North 
812 Atlantic domain are shown in cyan and variance estimates for global domain are shown in 813 dark blue.

814 

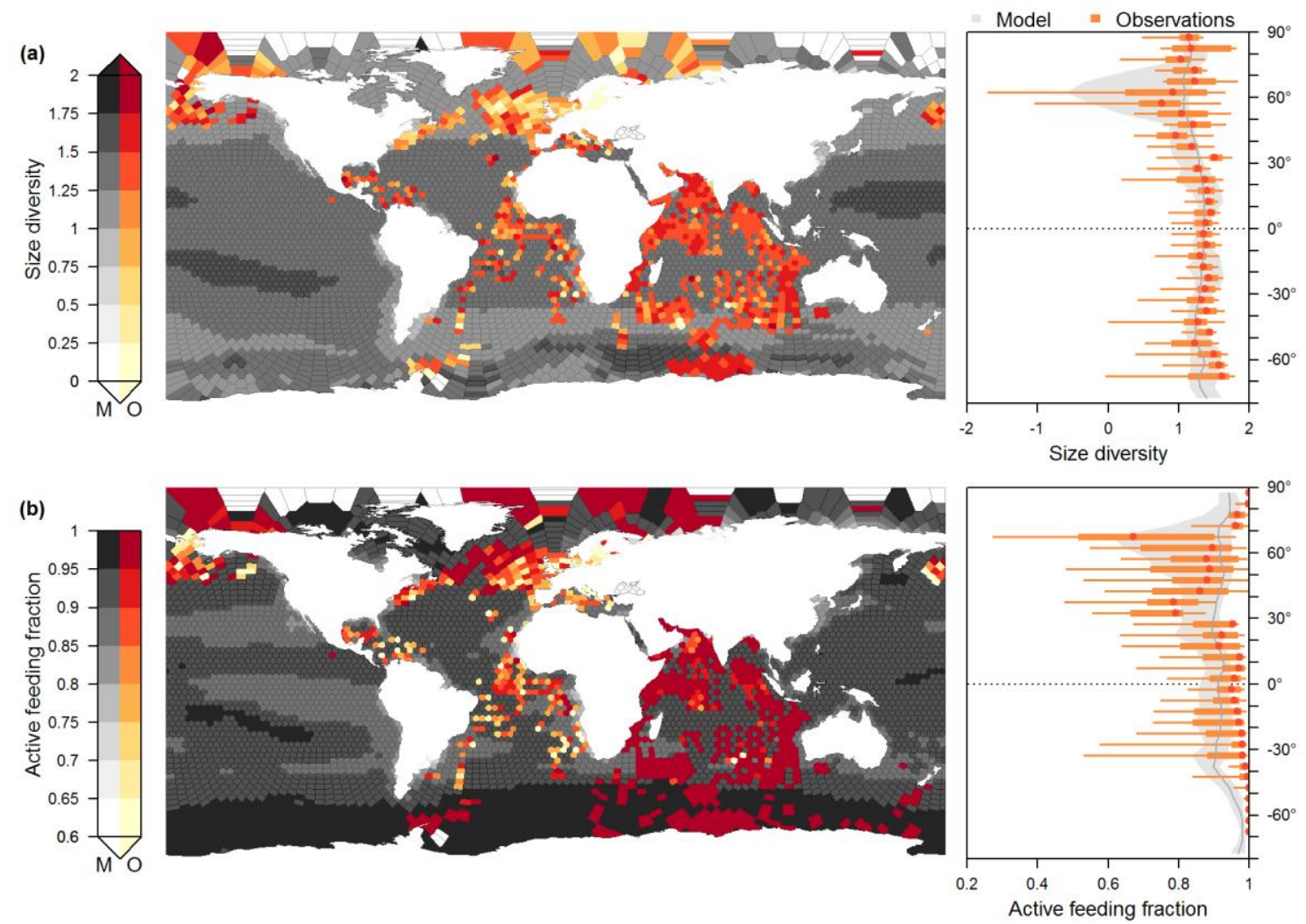

816

817 Global distributions of community mean traits for body-size diversity (a) and active

818 feeding (b). Polygons on the maps represent simulated communities. Colored polygons are

819 data-based estimates; polygons in gray scales are predictions with the best environmental

820 models. The panels on the right show latitudinal trait variation. Median model predictions

821 (lines) and 90\% confidence intervals (polygons) are shown in grey. Data-based trait patterns

822 are superimposed in orange, including median (circles), inter quartile range (thick lines), and

$82390 \%$ confidence intervals (thin lines). 
827 Atlantic obtained from spatiotemporal models. Depicted are means and standard deviations.

828 Temporal autocorrelation is defined as Pearson correlation coefficients between subsequent 829 seasons; spatial autocorrelation length is defined as the distance at which the Pearson 830 correlation coefficients between points fall below about 0.13 .

\begin{tabular}{lcc}
\hline Trait & $\begin{array}{c}\text { Temporal autocorrelation (between } \\
\text { seasons) }\end{array}$ & $\begin{array}{c}\text { Spatial autocorrelation } \\
\text { length (km) }\end{array}$ \\
\hline $\begin{array}{l}\text { Body size } \\
\text { Relative offspring } \\
\text { size }\end{array}$ & $0.511 \pm 0.054$ & $810 \pm 87$ \\
Myelination & $0.277 \pm 0.082$ & $1017 \pm 85$ \\
Active feeding & $0.243 \pm 0.073$ & $998 \pm 90$ \\
Mixed feeding & $0.406 \pm 0.069$ & $1074 \pm 127$ \\
$\begin{array}{l}\text { Passive feeding } \\
\text { Body-size } \\
\text { diversity }\end{array}$ & $0.522 \pm 0.066$ & $970 \pm 88$ \\
\hline
\end{tabular}

831

Table F2: Spatial autocorrelation length of trait distributions in the global ocean

833 obtained from spatial models. Depicted are means and standard deviations. Spatial

834 autocorrelation length is defined as the distance at which the Pearson correlation coefficients

835 between points fall below about 0.13 .

\begin{tabular}{lc}
\hline Trait & Spatial autocorrelation length $(\mathbf{k m})$ \\
\hline Body size & $5575 \pm 1286$ \\
Relative offspring size & $4117 \pm 787$ \\
Myelination & $30745 \pm 22955$
\end{tabular}


Active feeding

Body-size diversity

836

837

7
$2549 \pm 5$

$1721 \pm 316$ 


\section{Appendix G: Skill of environmental models with all}

841 Akaike information criterion (WAIC), and explained variance $\left(\mathrm{R}^{2}\right)$ of global environmental

842 models. Best models for each trait are highlighted in yellow.

\begin{tabular}{|c|c|c|c|c|c|}
\hline Response & Predictors & DIC & WAIC & $\mathbf{R}^{2}$ & $\begin{array}{l}\text { Best } \\
\text { model }\end{array}$ \\
\hline Feeding_mode.Active & & 521.80 & 521.01 & & 0 \\
\hline Feeding_mode.Active & diverCHL & 520.73 & 519.18 & 0.02 & 0 \\
\hline Feeding_mode.Active & meanNPP & 507.63 & 505.99 & 0.11 & 0 \\
\hline Feeding_mode.Active & medianPhyto & 523.12 & 521.56 & 0.00 & 0 \\
\hline Feeding_mode.Active & diverCHL \& medianPhyto & 521.52 & 519.13 & 0.03 & 0 \\
\hline Feeding_mode.Active & meanNPP \& diverCHL & 502.49 & 500.07 & 0.13 & 1 \\
\hline Feeding_mode.Active & meanNPP \& medianPhyto & 507.36 & 504.93 & 0.10 & 0 \\
\hline Feeding_mode.Active & $\begin{array}{l}\text { meanNPP \& diverCHL \& } \\
\text { medianPhyto }\end{array}$ & 503.62 & 500.35 & 0.14 & 0 \\
\hline Myelination & & 1103.57 & 1102.82 & & 0 \\
\hline Myelination & meanNPP & 1088.48 & 1086.95 & 0.08 & 0 \\
\hline Myelination & meanZSD & 1087.71 & 1084.27 & 0.12 & 0 \\
\hline Myelination & medianPhyto & 1083.23 & 1081.79 & 0.11 & 0 \\
\hline Myelination & meanNPP \& medianPhyto & 1029.80 & 1027.42 & 0.31 & 0 \\
\hline Myelination & meanZSD \& meanNPP & 1024.59 & 1022.14 & 0.34 & 0 \\
\hline Myelination & meanZSD \& medianPhyto & 1048.60 & 1044.45 & 0.26 & 0 \\
\hline Myelination & $\begin{array}{l}\text { meanZSD \& meanNPP \& } \\
\text { medianPhyto }\end{array}$ & 1019.67 & 1016.37 & 0.36 & 1 \\
\hline
\end{tabular}




\begin{tabular}{|c|c|c|c|c|c|}
\hline OffspringSize & & 2652.67 & 2655.54 & & 0 \\
\hline OffspringSize & meanNPP & 2575.61 & 2574.39 & 0.11 & 0 \\
\hline OffspringSize & meanZSD & 2563.92 & 2563.02 & 0.12 & 0 \\
\hline OffspringSize & medianPhyto & 2450.52 & 2452.46 & 0.22 & 0 \\
\hline OffspringSize & meanNPP \& medianPhyto & 2325.52 & 2328.54 & 0.33 & 1 \\
\hline OffspringSize & meanZSD \& meanNPP & 2380.24 & 2380.92 & 0.29 & 0 \\
\hline OffspringSize & meanZSD \& medianPhyto & 2347.13 & 2349.12 & 0.32 & 0 \\
\hline OffspringSize & $\begin{array}{l}\text { meanZSD \& meanNPP \& } \\
\text { medianPhyto }\end{array}$ & 2331.31 & 2331.70 & 0.33 & 0 \\
\hline Size & & 2748.86 & 2749.15 & & 0 \\
\hline Size & diverCHL & 2663.16 & 2667.00 & 0.10 & 0 \\
\hline Size & meanNPP & 2621.78 & 2621.75 & 0.15 & 0 \\
\hline Size & meanSST & 2316.70 & 2324.12 & 0.41 & 0 \\
\hline Size & medianPhyto & 2530.59 & 2533.88 & 0.24 & 0 \\
\hline Size & diverCHL \& medianPhyto & 2363.88 & 2367.20 & 0.38 & 0 \\
\hline Size & meanNPP \& diverCHL & 2294.15 & 2295.89 & 0.42 & 0 \\
\hline Size & meanNPP \& medianPhyto & 2265.79 & 2266.23 & 0.44 & 0 \\
\hline Size & meanSST \& diverCHL & 2197.55 & 2203.25 & 0.50 & 0 \\
\hline Size & meanSST \& meanNPP & 2160.57 & 2168.47 & 0.52 & 0 \\
\hline Size & meanSST \& medianPhyto & 2174.24 & 2182.39 & 0.51 & 0 \\
\hline Size & $\begin{array}{l}\text { meanNPP \& diverCHL \& } \\
\text { medianPhyto }\end{array}$ & 2241.91 & 2242.00 & 0.46 & 0 \\
\hline Size & $\begin{array}{l}\text { meanSST \& diverCHL \& } \\
\text { medianPhyto }\end{array}$ & 2134.15 & 2145.48 & 0.53 & 0 \\
\hline Size & $\begin{array}{l}\text { meanSST \& meanNPP \& } \\
\text { diverCHL }\end{array}$ & 2147.14 & 2156.90 & 0.52 & 0 \\
\hline Size & $\begin{array}{l}\text { meanSST \& meanNPP \& } \\
\text { medianPhyto }\end{array}$ & 2130.55 & 2142.20 & 0.54 & 0 \\
\hline
\end{tabular}




\begin{tabular}{|c|c|c|c|c|c|}
\hline Size & $\begin{array}{l}\text { meanSST \& meanNPP \& } \\
\text { diverCHL \& medianPhyto }\end{array}$ & 2089.48 & 2106.09 & 0.56 & 1 \\
\hline Size_diversity & & 988.22 & 995.21 & & 0 \\
\hline Size_diversity & diverCHL & 756.29 & 770.96 & 0.27 & 0 \\
\hline Size_diversity & meanNPP & 624.68 & 631.16 & 0.38 & 0 \\
\hline Size_diversity & meanSST & 911.16 & 923.45 & 0.11 & 0 \\
\hline Size_diversity & medianPhyto & 855.45 & 867.05 & 0.16 & 0 \\
\hline Size_diversity & diverCHL \& medianPhyto & 751.58 & 761.19 & 0.27 & 0 \\
\hline Size_diversity & meanNPP \& diverCHL & 623.02 & 630.48 & 0.39 & 0 \\
\hline Size_diversity & meanNPP \& medianPhyto & 596.43 & 610.23 & 0.41 & 0 \\
\hline Size_diversity & meanSST \& diverCHL & 721.89 & 736.67 & 0.31 & 0 \\
\hline Size_diversity & meanSST \& meanNPP & 594.31 & 602.39 & 0.41 & 0 \\
\hline Size_diversity & meanSST \& medianPhyto & 721.33 & 732.50 & 0.31 & 0 \\
\hline Size_diversity & $\begin{array}{l}\text { meanNPP \& diverCHL \& } \\
\text { medianPhyto }\end{array}$ & 588.82 & 599.09 & 0.42 & 0 \\
\hline Size_diversity & $\begin{array}{l}\text { meanSST \& diverCHL \& } \\
\text { medianPhyto }\end{array}$ & 680.14 & 697.85 & 0.35 & 0 \\
\hline Size_diversity & $\begin{array}{l}\text { meanSST \& meanNPP \& } \\
\text { diverCHL }\end{array}$ & 597.90 & 605.54 & 0.41 & 0 \\
\hline Size_diversity & $\begin{array}{l}\text { meanSST \& meanNPP \& } \\
\text { medianPhyto }\end{array}$ & 581.59 & 595.75 & 0.43 & 1 \\
\hline Size_diversity & $\begin{array}{l}\text { meanSST \& meanNPP \& } \\
\text { diverCHL \& medianPhyto }\end{array}$ & 582.21 & 596.36 & 0.43 & 0 \\
\hline
\end{tabular}


845 Akaike information criterion (WAIC), and explained variance $\left(\mathrm{R}^{2}\right)$ of North Atlantic

846 environmental models. Best models for each trait are highlighted in yellow.

\begin{tabular}{|c|c|c|c|c|c|}
\hline Response & Predictors & DIC & WAIC & $\mathbf{R}^{2}$ & $\begin{array}{l}\text { Best } \\
\text { mode } \\
\text { l }\end{array}$ \\
\hline Feeding_mode.Active & & 215857 & 215863 & 0.00 & 0 \\
\hline Feeding_mode.Active & Diver_CHL & 210778 & 210784 & 0.01 & 0 \\
\hline Feeding_mode.Active & NPP & 208409 & 208410 & 0.02 & 0 \\
\hline Feeding_mode.Active & Phyto_size & 211310 & 211312 & 0.01 & 0 \\
\hline Feeding_mode.Active & Diver_CHL \& Phyto_size & 210529 & 210536 & 0.04 & 0 \\
\hline Feeding_mode.Active & NPP \& Diver_CHL & 208143 & 208149 & 0.02 & 0 \\
\hline Feeding_mode.Active & NPP \& Phyto_size & 207843 & 207845 & 0.04 & 0 \\
\hline Feeding_mode.Active & $\begin{array}{l}\text { NPP \& Diver_CHL \& } \\
\text { Phyto_size }\end{array}$ & 207459 & 207469 & 0.06 & 1 \\
\hline Myelination & & 242754 & 242757 & 0.00 & 0 \\
\hline Myelination & NPP & 241690 & 241692 & 0.07 & 0 \\
\hline Myelination & Phyto_size & 242291 & 242294 & 0.01 & 0 \\
\hline Myelination & ZSD & 242179 & 242183 & 0.04 & 0 \\
\hline Myelination & NPP \& Phyto_size & 240331 & 240334 & 0.11 & 0 \\
\hline Myelination & NPP \& ZSD & 241302 & 241306 & 0.08 & 0 \\
\hline Myelination & ZSD \& Phyto_size & 240022 & 240027 & 0.14 & 0 \\
\hline Myelination & NPP \& ZSD \& Phyto_size & 239348 & 239353 & 0.16 & 1 \\
\hline OffspringSize & & 86733 & 86734 & 0.00 & 0 \\
\hline OffspringSize & NPP & 85972 & 85972 & 0.03 & 0 \\
\hline OffspringSize & Phyto_size & 86061 & 86062 & 0.02 & 0 \\
\hline
\end{tabular}




\begin{tabular}{|c|c|c|c|c|c|}
\hline OffspringSize & ZSD & 86157 & 86159 & 0.02 & 0 \\
\hline OffspringSize & NPP \& Phyto_size & 84842 & 84841 & 0.06 & 0 \\
\hline OffspringSize & NPP \& ZSD & 85256 & 85257 & 0.05 & 0 \\
\hline OffspringSize & ZSD \& Phyto_size & 85196 & 85197 & 0.05 & 0 \\
\hline OffspringSize & NPP \& ZSD \& Phyto_size & 84145 & 84147 & 0.09 & 1 \\
\hline Size & & 97476 & 97478 & 0.00 & 0 \\
\hline Size & Diver_CHL & 92815 & 92823 & 0.04 & 0 \\
\hline Size & NPP & 94444 & 94444 & 0.08 & 0 \\
\hline Size & Phyto_size & 93403 & 93409 & 0.03 & 0 \\
\hline Size & SST & 90243 & 90251 & 0.11 & 0 \\
\hline Size & Diver_CHL \& Phyto_size & 95434 & 95435 & 0.06 & 0 \\
\hline Size & NPP \& Diver_CHL & 92736 & 92735 & 0.12 & 0 \\
\hline Size & NPP \& Phyto_size & 91645 & 91645 & 0.15 & 0 \\
\hline Size & NPP \& SST & 89445 & 89444 & 0.21 & 0 \\
\hline Size & SST \& Diver_CHL & 92424 & 92424 & 0.13 & 0 \\
\hline Size & SST \& Phyto_size & 89597 & 89612 & 0.13 & 0 \\
\hline Size & $\begin{array}{l}\text { NPP \& Diver_CHL \& } \\
\text { Phyto_size }\end{array}$ & 91088 & 91086 & 0.17 & 0 \\
\hline Size & NPP \& SST \& Diver_CHL & 89219 & 89216 & 0.21 & 0 \\
\hline Size & NPP \& SST \& Phyto_size & 84696 & 84736 & 0.23 & 0 \\
\hline Size & $\begin{array}{l}\text { SST \& Diver_CHL \& } \\
\text { Phyto_size }\end{array}$ & 92156 & 92155 & 0.14 & 0 \\
\hline Size & $\begin{array}{l}\text { NPP \& SST \& Diver_CHL \& } \\
\text { Phyto_size }\end{array}$ & 84477 & 84485 & 0.23 & 1 \\
\hline Size_diversity & & 49562 & 49559 & 0.01 & 0 \\
\hline Size_diversity & Diver_CHL & 48154 & 48157 & 0.05 & 0 \\
\hline Size_diversity & NPP & 45518 & 45513 & 0.13 & 0 \\
\hline
\end{tabular}




\begin{tabular}{llcrrr}
\hline Size_diversity & Phyto_size & 49191 & 49188 & 0.02 & 0 \\
Size_diversity & SST & 48973 & 48974 & 0.03 & 0 \\
Size_diversity & Diver_CHL \& Phyto_size & 48086 & 48086 & 0.05 & 0 \\
Size_diversity & NPP \& Diver_CHL & 45267 & 45263 & 0.13 & 0 \\
Size_diversity & NPP \& Phyto_size & 45295 & 45291 & 0.13 & 0 \\
Size_diversity & NPP \& SST & 45379 & 45375 & 0.13 & 0 \\
Size_diversity & SST \& Diver_CHL & 47922 & 47921 & 0.06 & 0 \\
Size_diversity & SST \& Phyto_size & 48662 & 48671 & 0.04 & 0 \\
Size_diversity & NPP \& Diver_CHL \& & 44943 & 44943 & 0.14 & 0 \\
Size_diversity & NPyto_size & & & & \\
Size_diversity & NPP \& SST \& Phyto_size & 45171 & 45168 & 0.14 & 0 \\
Size_diversity & $\begin{array}{l}\text { SST \& Diver_CHL \& } \\
\text { Phyto_size }\end{array}$ & 47851 & 47846 & 0.06 & 0 \\
Size_diversity & $\begin{array}{l}\text { NPP \& SST \& Diver_CHL \& } \\
\text { Phyto_size }\end{array}$ & 44855 & 44857 & 0.15 & 1 \\
\hline
\end{tabular}



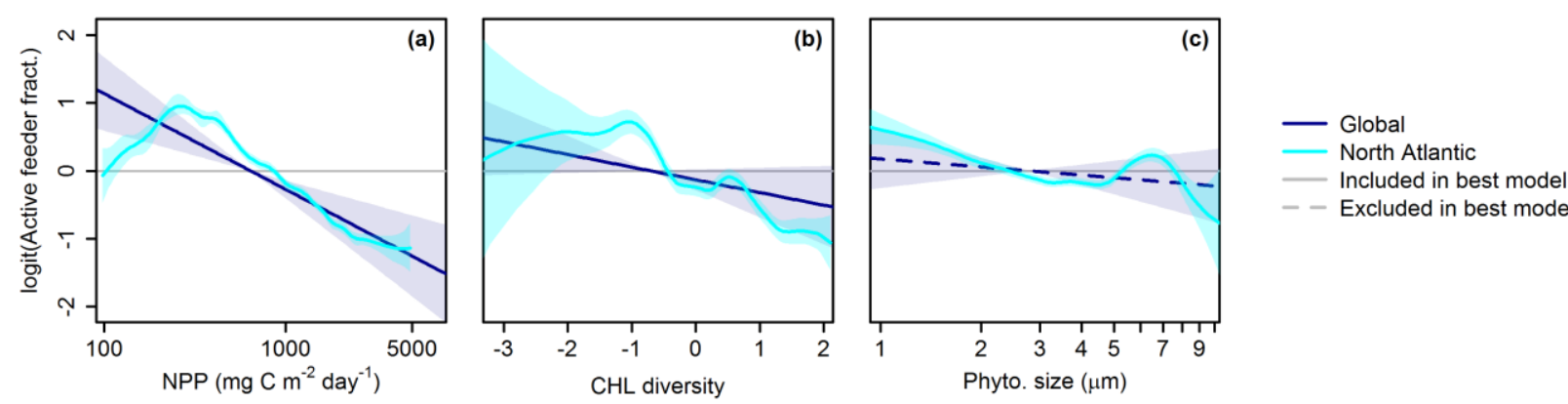

Responses of active feeding to environmental predictors of hypothetical importance,

851 based on single-predictor models. Responses are shown on the logit scale. Environmental

852 predictors are net primary production, seasonality of chlorophyll $a$ concentration, and

853 phytoplankton cell diameter (columns). Lines in dark blue represent global models, lines in cyan represent North Atlantic models. Shaded areas surrounding the lines illustrate 95\% confidence intervals. Dashed lines represent predictors not included in the best models of the corresponding trait and domain. 